\title{
Deskripsi Karakteristik Individu Transmigran di Kabupaten Banyuasin dan Ogan Ilir Provinsi Sumatera Selatan
}

\author{
Malta $^{1 *}$ \\ ${ }^{1}$ Fakultas Mipa, Program Studi Agribisnis Universitas terbuka UPBJJ-UT Banda Aceh, Indonesia. \\ *Email korespondensi: malta@ecampus.ut.ac.id
}

Diterima 31 Desember 2018; Disetujui 19 April 2019; Dipublikasi 30 April 2019

\begin{abstract}
Transfer of population is not only based on geographical inequality, but more important is to produce capital and human resources more optimally. the characteristics of transmigrants need attention, because this will affect the quality and performance of transmigrants at the transmigration site. The purpose of this study was to analyze the characteristics of transmigrant individuals. The study was conducted from May 2016 to January 2017. The total population was 3,537 transmigrant households. The number of the samples in this study was determined using Slovin formula. The study involved 359 respondents determined by stratified random sampling. The research data consisted of primary data and secondary data. The primary data was obtained through structured interviews, in-depth interviews, and field observations. The results of the study showed that the majority of transmigrants were of productive age (41-65 years), formal education was low, the majority of experiences were 10 years of farming, most of the experience was following transmigration for 11-15 years, and motivation to participate in transmigration programs to obtain agricultural land.
\end{abstract}

Keywords: individual characteristics, transmigrant, transmigration

Abstrak: Pemindahan penduduk bukan hanya didasari oleh ketimpangan secara geografis, namun yang lebih penting adalah untuk menghasilkan sumber daya modal dan manusia secara lebih optimal. Karakteristik dari transmigran perlu mendapat perhatian, sebab hal tersebut akan memengaruhi kualitas dan kinerja transmigran di lokasi transmigrasi.Tujuan penelitian ini adalah menganalisis karakteristik individu transmigran. Penelitian dilakukan mulai Mei 2016 sampai Januari 2017. Jumlah populasi adalah 3.537 rumah tangga transmigran. Besarnya sampel dalam penelitian ini ditentukan dengan menggunakan rumus Slovin. Jumlah sampel sebanyak 359 responden. Penarikan sampel secara acak berstrata (stratified random sampling). Data penelitian terdiri dari data primer dan data sekunder. Data primer diperoleh melalui wawancara terstruktur, wawancara mendalam, dan pengamatan di lapangan. Hasil penelitian menemukan bahwa mayoritas transmigran berumur produktif (41-65 tahun), pendidikan formal rendah, mayoritas pengalaman berusaha tani>10 tahun, sebagian besar pengalaman mengikuti transmigrasi selama 11-15 tahun, serta motivasi ikut program transmigrasi untuk mendapatkan lahan pertanian.

Kata kunci: karakteristik individu, transmigran, transmigrasi 
Sejak zaman pemerintah kolonial Belanda, kegiatan pemindahan penduduk di Indonesia telah dilaksanakan. Pada masa itu, pemindahan tersebut bertujuan untuk mengatasi kekurangan tenaga kerja di tempattempat perkebunan. Seterusnya, dengan versi yang berbeda kegiatan pemindahan penduduk yang dikenal dengan istilah transmigrasi telah dilanjutkan pada masa Orde Lama, Orde Baru, dan era Otonomi. Pada masa Orde Baru, tujuan ganda program transmigrasi dinyatakan sebagai usaha mencapai penyebaran penduduk secara lebih seimbang dan pemindahan tenaga kerja untuk melaksanakan proyek-proyek pembangunan di daerah yang kekurangan tenaga kerja. Dalam hal ini, yang menjadi sasaran utama bukanlah sekedar memindahkan penduduk, namun yang amat penting adalah meningkatkan produksi nasional melalui explorasi potensi ekonomi daerah, peningkatan produksi dan pendapatan transmigran (Yuniawardi, 1993).

Sejalan dengan bergulirnya waktu, program transmigrasi semakin ditingkatkan dengan jalan mengaitkan program tersebut dengan program integrasi nasional yang bertujuan untuk mempersatukan antar suku dalam upaya menciptakan kerukunan nasional menuju ketahanan nasional yang tangguh. Penyebaran penduduk yang merata diharapkan akan memberikan dorongan dan rangsangan terhadap peningkatan pembangunan di daerah-daerah yang perkembangannya masih relatif rendah dan diharapkan akan tercipta laju pertumbuhan yang serasi antar daerah di seluruh Indonesia. Pemindahan penduduk bukan hanya didasari oleh ketimpangan secara geografis, namun yang lebih penting adalah untuk menghasilkan sumber daya modal dan manusia secara lebih optimal. Diharapkan program transmigrasi berperan sebagai pendorong laju pertumbuhan ekonomi terutama untuk sektor pertanian dan industri kecil yang banyak digeluti oleh penduduk Indonesia.

Untuk terwujudnya tujuan program transmigrasi, di samping perlu adanya pendekatan yang tepat dari penanggung jawab program (kementerian dan pemda), dan tidak terlepas dari pihak transmigran sendiri. Sebaik apa pun program yang dirancang oleh pemerintah tanpa diikuti oleh kesadaran serta partisipasi dari transmigran, maka program tersebut tidak akan membawa hasil seperti yang diharapkan. Untuk itu karakteristik dari transmigran perlu mendapat perhatian, sebab hal tersebut akan memengaruhi kualitas dan kinerja transmigran di lokasi transmigrasi, seperti dalam pengambilan keputusan serta beraktivitas di tempat tujuan.

Bagaimana karakteristik individu transmigran sangat penting dikaji, yang selanjutnya dapat dijadikan sebagai dasar dalam pengembangan masyarakat dan kawasan transmigrasi. Tujuan penelitian ini adalah menganalisis karakteristik individu transmigran. 


\section{METODE PENELITIAN}

Jenis penelitian yang digunakan adalah penelitian deskriptif (descriptive research) yaitu menjelaskan subyek penelitian seperti profil individu/kelompok, proses, mekanisme atau hubungan, memberikan gambaran verbal dan numerik, menelusuri informasi untuk menjelaskan temuan, atau berbagai hal yang bertentangan dengan kepercayaan (Neuman, 1994). Penelitian dilakukan bulan Mei 2016 sampai Januari 2017. Lokasi penelitian di Kabupaten Banyuasin dan Ogan Ilir Provinsi Sumatera Selatan, dengan pertimbangan merupakan kawasan dengan jumlah transmigran yang besar di Provinsi Sumatera Selatan. Jumlah populasi adalah 3.537 rumah tangga transmigran. Besarnya sampel dalam penelitian ini ditentukan dengan menggunakan rumus Slovin. Jumlah sampel sebanyak 359 responden. Penarikan sampel secara acak berstrata (stratified random sampling). Pengumpulan data dilakukan untuk mendapatkan data primer dan data sekunder. Data primer diperoleh melalui wawancara terstruktur, wawancara mendalam, dan pengamatan di lapangan.

\section{HASIL DAN PEMBAHASAN}

Gambaran karakteristik individu transmigran pada di Kabupaten Banyuasin dan Ogan Ilir Provinsi Sumatera Selatan adalah: mayoritas berumur produktif, pendidikan formal rendah, mayoritas pengalaman berusaha tani $>10$ tahun, sebagian besar pengalaman mengikuti transmigrasi selama 11-15 tahun, serta motivasi sedang (Tabel 1). Makna motivasi sedang adalah, bahwa mayoritas transmigran mau ikut program transmigrasi karena alasan mendapatkan lahan pertanian dan menjadi pemilik tanah.

Kondisi di atas adalah juga menggambarkan kondisi sosial masyarakat transmigran di lokasi penelitian. Secara lebih terinci penjelasan masing-masing karakteristik individu tersebut diuraikan lebih lanjut.

\section{Umur}

Umur sebagian besar transmigran (96,1 persen) berada pada umur produktif, hanya sebagian kecil (3,9 persen) yang berumur lebih dari 65 tahun. Umur produktif mengacu pada rentang umur 15 sampai 65 tahun (BPS, 2001).

Persyaratan umum untuk menjadi transmigran adalah sudah berkeluarga dan berumur antara 18 sampai dengan 50 tahun, sesuai tahun lahir pada Kartu Tanda Penduduk (KTP). Terdapat 3,9 persen transmigran yang berumur di atas 65 tahun, sedangkan pengalaman menjadi transmigran di lokasi penelitian berkisar 6-15 tahun; yang berarti pada waktu berangkat dari daerah asal berumur di atas 50 tahun. Hal ini terjadi karena alasan pemenuhan target jumlah transmigran yang diberangkatkan dan juga terdapat tahun lahir pada KTP transmigran yang tidak sesuai dengan yang sebenarnya. 
Tabel 1 Sebaran responden berdasarkan karakteristik individu di Banyuasin dan Ogan Ilir Tahun 2016

\begin{tabular}{|c|c|c|c|c|}
\hline \multirow{3}{*}{ Karakteristik Individu } & \multirow{3}{*}{ Kategori } & \multicolumn{2}{|c|}{ Kabupaten } & \multirow[b]{2}{*}{$\begin{array}{c}\text { Total } \\
(n=359)\end{array}$} \\
\hline & & $\begin{array}{c}\text { Banyuasin } \\
(n=284)\end{array}$ & $\begin{array}{c}\text { Ogan Ilir } \\
(n=75)\end{array}$ & \\
\hline & & $\%$ & $\%$ & $\%$ \\
\hline & $31-40$ tahun & 15,5 & 25,3 & 17,8 \\
\hline Umur & 41-65 tahun & 79,6 & 74,7 & 78,3 \\
\hline \multirow[t]{3}{*}{ Rataan: 47,1} & 66-70 tahun & 4,9 & 0,0 & 3,9 \\
\hline & Jumlah & 100,0 & 100,0 & 100,0 \\
\hline & 2-6 tahun & 72,2 & 61,3 & 69,9 \\
\hline Pendidikan formal & 7-9 tahun & 26,4 & 36,0 & 28,4 \\
\hline \multirow{2}{*}{ Rataan: 6,2} & 10-12 tahun & 1,4 & 2,7 & 1,7 \\
\hline & Jumlah & 100,0 & 100,0 & 100,0 \\
\hline \multirow{4}{*}{$\begin{array}{l}\text { Pengalaman } \\
\text { berusaha tani* } \\
\text { Rataan: } 16,1\end{array}$} & $<10$ tahun & 7,4 & 38,7 & 13,9 \\
\hline & 11-30 tahun & 91,9 & 61,3 & 85,5 \\
\hline & $>30$ tahun & 0,7 & 0,0 & 0,6 \\
\hline & Jumlah & 100,0 & 100,0 & 100,0 \\
\hline \multirow{3}{*}{$\begin{array}{l}\text { Pengalaman } \\
\text { menjadi transmigran** } \\
\text { Rataan: } 12,2\end{array}$} & $<10$ tahun & 12,7 & 74,7 & 25,6 \\
\hline & 11-15 tahun & 87,3 & 25,3 & 74,4 \\
\hline & Jumlah & 100,0 & 100,0 & 100,0 \\
\hline \multirow{4}{*}{$\begin{array}{l}\text { Motivasi } \\
\text { menjadi transmigran } \\
\text { Rataan skor: } 69,8\end{array}$} & Rendah & 29,9 & 25,3 & 29,0 \\
\hline & Sedang & 33,1 & 30,7 & 32,6 \\
\hline & Tinggi & 37,0 & 44,0 & 38,4 \\
\hline & Jumlah & 100,0 & 100,0 & 100,0 \\
\hline
\end{tabular}

Keterangan: * beda nyata pada $\alpha=0,05 ; \quad * *$ beda sangat nyata pada $\alpha=0,01$ Nilai rataan skor: Rendah $=0-50$, Sedang $=51-75$, Tinggi $=76-100$

Kondisi usia produktif, pada usia tersebut memiliki semangat, daya juang (karsa), inisiatif, tidak lamban, dan tidak mudah menyerah. Pada usia dewasa, partisipasi aktif dalam masyarakat dan sense responsibility masih tinggi. Hurlock (1991) mengemukakan bahwa usia dewasa, merupakan masa pengaturan dimana seseorang mulai menerima tanggungjawab sebagai seorang dewasa, masa penyesuaian diri dengan cara hidup baru, dan masa kreatif (masa puncak kreativitas). Kehidupan sebagai transmigran, membutuhkan semangat, daya juang, dan kreativitas yang tinggi untuk menghadapi tantangan hidup dalam kondisi alam serta lingkungan sosial, ekonomi, dan budaya yang baru dan berbeda dengan kondisi di daerah asal.

Umur berperan dalam meningkatkan kemampuan seseorang dalam menjalankan suatu usaha, baik dari aspek kognitif, afektif, maupun keterampilan fisik. Menurut Klausmeier dan Goodwin (1966), usia merupakan salah satu karakteristik penting yang berkaitan dengan efisiensi dan efektivitas belajar. Hal ini mengandung arti bahwa individu yang berada pada usia produktif akan lebih mudah menerima perubahan, ide-ide, dan inovasi. Mengamati rentang umur transmigran, merupakan aset sumber daya manusia yang perlu diperhatikan untuk dikembangkan. Hal ini mengingat bahwa pengelolaan usaha tani di 
lokasi transmigrasi memerlukan sumber daya manusia yang produktif sehingga mampu mengelola usaha tani dengan optimal.

Umur yang lebih muda, secara fisik juga memiliki kekuatan yang lebih besar dibandingkan umur yang lebih tua. Pada kegiatan usaha tani, fisik yang prima diperlukan untuk menjalankan usaha, terutama pada aspek produksi, mulai dari persiapan pengolahan tanah, penanaman, pemeliharaan, hingga panen dan pascapanen.

Berdasarkan pengkategorian umur, jika dilihat dari rataan usia antara transmigran/petani di kedua kabupaten, terlihat bahwa transmigran/petani di Banyuasin rataan usia berada pada usia 47,8 tahun dan Ogan Ilir pada usia 44,4 tahun. Penelitian Rachmawati dan Saleh (2009) di Kabupaten Bogor serta Muhibuddin et al., (2015) di Aceh, juga memperlihatkan hal yang sama. Rata-rata umur petani di Kabupaten Bogor berkisar pada usia 40-an (48 tahun), dan di Aceh umur rata-ratanya 44,7 tahun.

\section{Pendidikan Formal}

Tingkat pendidikan formal sebagian besar transmigran (69,9 persen) di kedua kabupaten pada kisaran 2-6 tahun, dengan rata-rata 6,2 tahun atau tamatan Sekolah Dasar (SD). Hasil penelitian ini sejalan dengan temuan Harmadi dan Antarwati (2014), bahwa individu atau masyarakat dengan pendidikan rendah memiliki kecenderungan yang tinggi untuk bekerja dan tinggal di daerah perdesaan melalui migrasi antar pulau. Rendahnya tingkat pendidikan formal di lokasi penelitian, menunjukkan bahwa pendidikan formal belum menjadi tujuan utama masyarakat asal trasmigran, masih lemahnya ekonomi keluarga sehingga masih sulit untuk dapat menyekolahkan anak sampai perguruan tinggi, serta kurangnya minat anak usia sekolah untuk melanjutkan ke jenjang lanjutan.

Tingkat pendidikan dapat memengaruhi respons seseorang terhadap inovasi (Rogers, 2003). Rendahnya tingkat pendidikan transmigran dapat menjadi penyebab rendahnya kemampuan dalam pengelolaan usaha tani, yang dapat menjadi penghambat bagi peningkatan produksi usaha tani dan pengelolaan usaha yang berkelanjutan.

Pendidikan formal sangat penting bagi seseorang untuk mengembangkan kapasitas dirinya, karena dengan mengenyam pendidikan formal yang lebih tinggi, maka pengalaman belajar dan wawasan pengetahuan yang diperoleh juga akan meningkat. Berbekal pengalaman dan pengetahuan ini dapat dikembangkan sikap yang positif dan keterampilan yang lebih baik. Bagi transmigran, pengetahuan yang tinggi, sikap yang positif, dan keterampilan yang tinggi akan menjadikan dirinya mampu dalam membangun hubungan kerja sama, mengantisipasi kemungkinan perubahan, serta berkomitmen terhadap mutu komoditas yang dihasilkan. Menurut UNDP (1998), melalui pendidikan akan menjadikan 
seseorang berani mengembangkan pikiran, ide, berbicara, dan memiliki impian.

Berdasarkan

pengkategorian

pendidikan formal, rataan pendidikan transmigran di Kabupaten Ogan Ilir memiliki rataan pendidikan lebih tinggi (7,1 tahun) dibandingkan di Banyuasin (6,0 tahun). Namun tidak terdapat perbedaan nyata tingkat pendidikan formal transmigran pada dua kabupaten tersebut.

\section{Pengalaman}

Terdapat dua jenis pengalaman yang diukur dalam penelitian ini, yaitu: pengalaman berusaha tani dan pengalaman menjadi transmigran. Pengalaman dalam berusaha tani yang diukur adalah pengalaman transmigran berusaha tani selama di daerah asal ditambah pengalaman berusaha tani di lokasi transmigrasi. Rata-rata transmigran telah menjalankan kegiatan usaha tani selama 16,1 tahun, dengan variasi antara 6 hingga 33 tahun. Sebagian besar (85,5 persen) transmigran memiliki pengalaman berusaha tani pada kisaran 11-30 tahun. Pengalaman dalam mengikuti program transmigrasi sebagai transmigran pada kisaran 6-15 tahun, dengan rataan 12,2 tahun. Sebagian besar (74,4 persen) transmigran punya pengalaman ikut program transmigrasi selama 11-15.

Transmigran di Kabupaten Banyuasin memiliki rataan pengalaman berusaha tani selama 16,6 tahun, sedangkan transmigran di Ogan Ilir selama 13,9 tahun. Transmigran di Kabupaten Banyuasin memiliki rataan pengalaman dalam mengikuti program transmigrasi lebih lama (13,2 tahun), jika dibandingkan transmigran di Ogan Ilir yaitu selama 8,8 tahun. Secara nyata terdapat perbedaan tingkat pengalaman transmigran dalam berusaha tani serta tingkat pengalaman mengikuti program transmigrasi pada dua kabupaten tersebut.

Umumnya transmigran punya pengalaman berusaha tani sejak dari daerah asal, namun terdapat 31,2 persen transmigran yang tidak punya pengalaman berusaha tani di daerah asal. Para transmigran tersebut, di daerah asal bukan berprofesi sebagai petani dan baru memulai pekerjaan sebagai petani di lokasi transmigrasi. Penyelenggaraan transmigrasi di lokasi penelitian menerapkanp olausaha tani dan yang ditransmigrasikan adalah para petani atau keluarga/ masyarakat yang siap untuk menjalankan usaha di sektor pertanian. Penjaringan calon transmigran di daerah asal tidak hanya terbatas kepada para petani, tetapi juga individu atau keluarga yang bukan petani dan kemudian siap untuk berusaha tani di lokasi transmigrasi. Transmigran yang tidak punya pengalaman sebagai petani di daerah asal dan baru memulai pekerjaan usaha tani di lokasi transmigrasi, banyak mengalami kesulitan dalam beradaptasi dengan pekerjaan baru tersebut, ditambah kondisi tanah yang termasuk lahan suboptimal. Banyak yang mengalami gagal panen, yang berakibat tidak punya pendapatan dari usahanya sehingga kemudian 
sebagian kembali ke daerah asal setelah masa pemberian bantuan jatah hidup habis. Ketiadaan pengalaman berusaha tani di daerah asal (sebelum menjadi transmigran), menjadi salah satu faktor penyebab transmigran meninggalkan lokasi transmigrasi.

Pada tiga tahun pertama, para transmigran diarahkan untuk berusaha tani padi. Kondisi lahan di lokasi penelitian (lahan rawa) yang kurang adaptif terhadap tanaman padi dan di sisi lain keterbatasan kemampuan transmigran untuk mengelola usaha tani padi di lahan rawa, sehingga sering terjadi kegagalan dalam proses produksi dan panen. Keadaan ini menyebabkan para transmigran beralih menanam komoditas tanaman perkebunan yaitu karet dan kelapa sawit.

Pengalaman berusaha tani merupakan salah satu factor penting bagi transmigran untuk menjalankan kegiatan usaha tani. Pengalaman berusaha tani ikut membentuk kemampuan dalam mengelola usaha tani, karena selama masa menjalankan usaha tani akan mengalami proses belajar, termasuk memperoleh pelajaran cara pengelolaan dan pengembangan usaha. Ada kecenderungan bahwa semakin banyak belajar dari pengalaman pribadi maupun transmigran lain yang berhasil, member dampak positif dalam menjalankan kegiatan usahatani. Pengalaman yang telah dimiliki oleh transmigran dalam berusaha tani biasanya ditularkan kepada sesame transmigran yang lain, sehingga mempermudah transmigran yang belum berpengalaman dalam suatu aspek tertentu, dalam melakukan pengembangan usahatani. Padmowiharjo (1994) menyatakan bahwa rangkaian setiap pengalaman yang berhasil merupakan suatu hasil proses belajar yang bersifat abstrak dan membentuk suatu petakognitif.

Pengalaman berusaha tani juga memiliki peranan yang sangat penting bagi transmigran dalam sikap dan keputusan menerima serta menerapkan teknologi baru. Sarwono (2002) menyebutkan bahwa pengalaman memiliki pengaruh terhadap perilaku individu. Sesuatu yang dialami oleh transmigran selama mengelola usaha taninya, akan menjadi bekal dalam membentuk dan memberikan kontribusi psikologis untuk merespons berbagai stimulus yang datang kepadanya. Pengalaman dalam mengelola usaha tani, berkaitan dengan pola perilaku transmigran terhadap lahan usaha yang pada akhirnya akan menentukan tingkat kemampuan/keberdayaan dalam mengelola usaha taninya.

\section{Motivasi Menjadi Transmigran}

Sebagian besar (48,5 persen) motivasi transmigran di lokasi penelitian, ikut program transmigrasi karena alasan mendapatkan lahan pertanian dan menjadi pemilik tanah (Tabel 2). Tidak terdapat perbedaan nyata tingkat motivasi transmigran untuk ikut program transmigrasi pada Kabupaten Banyuasin dan Ogan Ilir. 
Tabel 2 Persentase responden berdasarkan alasan menjadi transmigran di Banyuasin dan Ogan Ilir Tahun 2016

\begin{tabular}{lccc}
\hline & \multicolumn{2}{c}{ Kabupaten } \\
Alasan MenjadiTransmigran & $\begin{array}{c}\text { Banyuasin } \\
(\mathrm{n}=284)\end{array}$ & $\begin{array}{c}\text { Ogan } \\
\text { Ilir } \\
(\mathrm{n}=75)\end{array}$ & $\begin{array}{c}\text { Total } \\
(\mathrm{n}=359)\end{array}$ \\
\cline { 2 - 4 } & $\%$ & $\%$ & $\%$ \\
\hline $\begin{array}{l}\text { Tidak ada pilihan lain untuk keluar dari kesulitan mencari } \\
\text { penghasilan }\end{array}$ & 16,5 & 0,0 & 13,1 \\
$\begin{array}{l}\text { Karena dapat lahan pertanian } \\
\begin{array}{l}\text { Untuk mengembangkan kemampuan diri dengan hidup di daerah } \\
\text { baru }\end{array}\end{array}$ & 37,0 & 46,5 & 48,0 \\
\hline
\end{tabular}

Faktor ekonomi merupakan salah satu alasan seseorang atau sekelompok orang untuk melakukan migrasi. Menurut Todaro (1998) persentase migran terbesar terjadi pada orang-orang yang tidak memiliki tanah, keterbatasan kepemilikan asset, serta tidak memiliki kesempatan untuk maju di daerah asal.

Lahan/tanah juga merupakan simbol status social dalam masyarakat. Seseorang yang memiliki lahan/tanah yang lebih luas, dapat memberikan status sosial yang lebih tinggi. Sajogjo (Nasdian, 2015) menyatakan bahwa pemilikan lahan sebagai simbol golongan elit perdesaan. Menurut Polanyi (Levang, 2003), manusia bertindak sedemikian rupa adalah demi status sosial, hak, dan keuntungannya dalam masyarakat. Affandi (1985) menyebutkan bahwa daya tarik atas kepemilikan lahan yang luasnya itu antara 2-2,5 hektar per kepala keluarga yang diharapkan dapat meningkatkan pendapatan dan harga diri calon transmigran, memegang peranan yang cukup besar bagi calon transmigran dalam pengambilan keputusan untuk bertransmigrasi.

Motivasi dapat diartikan sebagai kekuatan (energi) seseorang yang dapat menimbulkan tingkat persistensi dan antusiasmenya dalam melaksanakan suatu kegiatan (Hartati, 2008). Motivasi untuk ikut program transmigrasi berkaitan dengan keberhasilan dalam menjalankan usaha tani, karena motivasi tersebut akan mewarnai kehidupan transmigran di lokasi transmigrasi.

Menurut McClelland (Barbutto et al., 2004) dan Bird (1989), bahwa motivasi terkait dengan kebutuhan seseorang. Seseorang memiliki motif atau dorongan untuk ikut program transmigrasi karena ada kebutuhan yang harus dipenuhi. Dorongan tersebut bisa disebabkan adanya faktor dari luar ataupun faktor internal atau keyakinan dan kepuasan internalnya; artinya ada tujuan yang akan dicapai yang memberi dorongan lebih kepada transmigran untuk ikut program transmigrasi.

Motivasi merupakan modal yang sangat penting bagi transmigran untuk 
menunjang kesuksesan dalam berusaha tani.

Perlu terus ditumbuhkan kesadaran transmigran terhadap kebutuhan lain yaitu kebutuhan sosial dan berkembang. Kesadaran terhadap kebutuhan tersebut, berarti ada tujuan lebih tinggi yang akan dicapai melalui program transmigrasi lebih dari tujuan mendapatkan lahan pertanian.

\section{Asal Daerah Transmigran}

Kebijakan program transmigrasi di lokasi penelitian, mengatur bahwa penempatan transmigran mengikut komposisi 50 persen penduduk daerah setempat dan 50 persen penduduk dari daerah pengirim. Asal daerah transmigran di lokasi penelitian adalah dari Provinsi Banten, Jawa Barat, Jawa Tengah, Yogyakarta, dan Jawa Timur. Provinsi asal transmigran, baik di Kabupaten Banyuasin maupun di Kabupaten Ogan Ilir, yang terbanyak berasal dari Jawa Timur
(Tabel 3). Program transmigrasi era Otonomi Daerah, menerapkan kerja sama antar daerah (KSAD). Berdasarkan potensi dan kebutuhan, pemerintah daerah pengirim transmigran, melakukan penjajakan kerja sama dengan pemerintah daerah tujuan penempatan transmigran. Pemerintah daerah asal/pengirim transmigran menentukan jumlah transmigran yang diberangkatkan dengan memerhatikan: (1) kebutuhan pengiriman transmigran untuk mengatasi keterbatasan peluang tempat tinggal, peluang berusaha, dan kesempatan bekerja di daerah asal, (2) kemampuan dukungan anggaran daerah, (3) kemauan dan kemampuan masyarakat untuk bertransmigrasi, (4) kualifikasi kompetensi penduduk yang memungkinkan bertransmigrasi, dan (5) ketersediaan lahan di daerah penerima transmigran.

Tabel 3 Persentase responden berdasarkan provinsi asal di Banyuasin dan Ogan Ilir Tahun 2016

\begin{tabular}{lccc}
\hline \multirow{2}{*}{ Provinsi Asal } & \multicolumn{2}{c}{ Kabupaten } & Total \\
\cline { 2 - 3 } & $\begin{array}{c}\text { Banyuasin } \\
(\mathrm{n}=122)\end{array}$ & $\begin{array}{c}\text { Ogan Ilir } \\
(\mathrm{n}=34)\end{array}$ & $\begin{array}{c}\text { Tol } \\
(\mathrm{n}=156)\end{array}$ \\
\cline { 2 - 3 } & $\%$ & $\%$ & $\%$ \\
\hline Banten & 1,6 & 0,0 & 1,3 \\
Jawa Barat & 20,5 & 23,5 & 21,2 \\
Jawa Tengah & 28,7 & 17,6 & 26,3 \\
Jawa Timur & 35,3 & 44,2 & 30,8 \\
Yogyakarta & 13,9 & 14,7 & 20,5 \\
\hline
\end{tabular}

Kota dan Kabupaten asal transmigran meliputi: Majalengka, Lumajang, Pacitan, Ciamis, Madiun, Purbalingga, Jepara, Yogyakarta, Bogor, Semarang, Tulung Agung, Ponorogo, Ngawi, Sleman,
Indramayu, Kuningan, Cianjur, Pandeglang, Cilacap, Pekalongan, Trenggalek, Magelang, dan Magetan. 


\section{KESIMPULAN}

Berdasarkan hasil dan pembahasan, maka disimpulkan beberapa hal sebagai berikut: karakteristik individu transmigran pada di Kabupaten Banyuasin dan Ogan Ilir Provinsi Sumatera Selatan adalah: mayoritas berumur produktif, pendidikan formal rendah, mayoritas pengalaman berusaha tani $>10$ tahun, sebagian besar pengalaman mengikuti transmigrasi selama 11-15 tahun, serta motivasi transmigran ikut program transmigrasi untuk mendapatkan lahan pertanian dan menjadi pemilik tanah.

\section{DAFTAR PUSTAKA}

Affandi MJ. (1985). Motivasi yang Mendasari Niat untuk Bertransmigrasi (Studi Kasus di Kabupaten Jembrana). Yogyakarta: Universitas Gajah Mada.

Barbutto JE, Trout SK, Brown LL. (2004). Identifying Sources Motivation of Adult Rural Workers. Journal of Agricultural Education. 45:3.

Bird BJ. (1989). Entrepreneurial Behavior. Illinois: Scott Foresman and Company.

[BPS] Badan Pusat Statistik. (2001). Proyeksi Penduduk, Angkatan Kerja, Tenaga Kerja, dan Peran Serikat Pekerja dalam Peningkatan Kesejahteraan. [diunduh 2 Jan 2008]. Tersedia pada: http://www.bps.go.id.

Hartati P. (2008). Motivasi Migrasi Pada Transmigrasi Umum di Unit Pemukiman Transmigrasi Pongkase
Kabupaten Luwu Utara. Jurnal Agrisistem. 4(1):12-17.

Hurlock EB. (1991). Psikologi Perkembangan: Suatu Pendekatan Sepanjang Rentang Kehidupan. Jakarta: Erlangga.

Klausmeier HJ, Goodwin W. (1966). Learning and Human Abilities: Educational Psycology. New York: Harper \& Row Publisher.

Levang P. (2003). Ayo ke Tanah Sabrang:

Transmigrasi di Indonesia. Pryoga SAW, penerjemah. Jakarta: Kepustakaan Populer Gramedia. Terjemahan dari: La terre d'en face La transmigration en Indonesie.

Muhibuddin, Amanah S, Sadono D. (2015). Tingkat Kompetensi Petani Agribisnis Sayuran Pada Lahan Sempit di Kota Banda Aceh dan Kabupaten Aceh Besar. Jurnal Penyuluhan. 11(2):186200.

Nasdian FT. (2015). Sosiologi Umum. Bogor: Institut Pertanian Bogor.

Neuman, L. (1994). Social Research Methods: Qualitative And Quantitative Approaches. Boston: Allyn and Bacon. Padmowihardjo S. (1994). Psikologi Belajar Mengajar. Jakarta: Universitas Terbuka.

Rachmawati N, Saleh A. (2009). Hubungan Karakteristik Petani dengan Jasa Pelayanan dan Efektivitas Komunikasi Klinik Agribisnis di Prima Tani Leuwi 
Jurnal Humaniora, Vol.3, No. 1, April 2019 : 61-71

http://jurnal.abulyatama.ac.id/index.php/humaniora

Sadeng Kabupaten Bogor. Jurnal

Komunikasi Pembangunan. 7(2):57-

67.

Rogers EM. (2003). Diffusion of Innovations.

London: Free Press.

Sarwono SW. (2002). Psikologi Sosial:

Individu dan Teori-Teori Psikologi

Sosial. Jakarta: Balai Pustaka.

Todaro M. (1998). Pembangunan Ekonomi di

Dunia Ketiga. Jakarta: Penerbit

Erlangga.

[UNDP] United Nations Development

Programme. (1998). Capacity

Assessment and Development: in a

System and Strategic Management

Context. Technical Advisory Paper 3,

UNDP.

Yuniawardi. (1993). Laporan Penelitian.

Padang: IKIP.

- How to cite this paper :

Malta, M. (2019). Deskripsi Karakteristik Individu Transmigran di Kabupaten Banyuasin dan Ogan Ilir Provinsi Sumatera Selatan. Jurnal Humaniora, 3(1), 61-71. 